\title{
Uso de metodologias ativas como estratégia no ensino remoto em um curso de
}

\section{Licenciatura em Ciências Biológicas}

\author{
Use of active methodologies as a strategy in remote education in a Biological Sciences graduation \\ course
}

Uso de metodologías activas como estrategia en educación a distancia en un curso de Ciencias

Biológicas

Recebido: 10/09/2021 | Revisado: 19/09/2021 | Aceito: 21/09/2021 | Publicado: 23/09/2021

\author{
Adervan Fernandes Sousa \\ ORCID: https://orcid.org/0000-0002-4096-9284 \\ Universidade Estadual do Ceará, Brasil \\ E-mail: adervan.sousa@uece.br \\ Jandson Araújo da Silva \\ ORCID: https://orcid.org/ 0000-0003-3177-014X \\ Universidade Estadual do Ceará, Brasil \\ E-mail: jandson.silva@aluno.uece.br \\ Fabrício Bonfim Sudério \\ ORCID: https://orcid.org/0000-0001-5937-5681 \\ Universidade Estadual do Ceará, Brasil \\ E-mail: fabricio.suderio@uece.br
}

\begin{abstract}
Resumo
Com a pandemia da covid-19, as instituições de ensino básico e de ensino superior foram obrigadas a continuarem os processos educativos por meio do ensino remoto. Diante disso, surgiram novos desafios tanto em relação ao uso de tecnologias quanto aos aspectos pedagógicos. Desta forma, o objetivo deste trabalho foi observar a viabilidade do uso de metodologias ativas com atividades síncronas e assíncronas no contexto de ensino remoto em um Curso de Licenciatura em Ciências Biológicas. O trabalho envolveu 11 alunos matriculados nas disciplinas de Ecologia e Ecologia Regional, da Faculdade de Educação de Crateús-Universidade Estadual do Ceará (FAEC-UECE) durante o semestre 2020.1. Na oportunidade, os estudantes elaboraram hipóteses para as questões sugeridas pelo professor e elaboraram argumentos que corroborassem ou não com as suas propostas. Para a coleta de dados, aplicou-se um questionário por meio do Google forms. De acordo os dados, os estudantes avaliaram positivamente o método utilizado por proporcionar melhor conhecimento em relação aos conteúdos das disciplinas e por desenvolver uma visão crítica da realidade local. Desta forma, pudemos concluir que a experiência vivenciada com o uso de Metodologias Ativas no ensino remoto nas disciplinas de Ecologia e Ecologia Regional propiciou um ambiente adequado de produção ativa dos estudantes e de consequente aprendizado.
\end{abstract}

Palavras-chave: Ensino remoto emergencial; Ensino de ecologia; Metodologias de ensino.

\begin{abstract}
With the covid-19 pandemic, basic and higher education institutions were forced to continue their educational processes through remote learning. Therefore, new challenges emerged both in relation to the use of technologies and pedagogical aspects. Thus, the objective of this work was to observe the feasibility of using active methodologies with synchronous and asynchronous activities in the context of remote teaching in a Biological Sciences Graduation Course. The work involved 11 students enrolled in the disciplines of Ecology and Regional Ecology at the Faculty of Education of Crateús-State University of Ceará (FAEC-UECE) during the semester 2020.1. On that occasion, the students elaborated hypotheses for the questions suggested by the professor and elaborated arguments that corroborated or not with their proposals. For data collection, a questionnaire was applied through Google forms. According to the data, the students study study if the method was used positively to provide the best information in the contents of the disciplines and to build the vision critique of the local reality. In this way, we were able to gain that the experience lived with the use of Active Methodologies in remote education in the subjects of Ecology and Regional Ecology provided an adequate environment for the active production of students and consequent learning.
\end{abstract}

Keywords: Emergency remote learning; Ecology teaching; Teaching methodologies. 


\begin{abstract}
Resumen
Con la pandemia del covid-19, las instituciones de educación básica y superior se vieron obligadas a continuar sus procesos educativos a través del aprendizaje a distancia. Por tanto, surgieron nuevos retos tanto en relación al uso de tecnologías como en aspectos pedagógicos. Así, el objetivo de este trabajo fue observar la viabilidad de utilizar metodologías activas con actividades sincrónicas y asincrónicas en el contexto de la enseñanza a distancia en una Licenciatura en Ciencias Biológicas. El trabajo involucró a 11 estudiantes matriculados en las disciplinas de Ecología y Ecología Regional, en la Facultad de Educación de Crateús-Universidad Estatal de Ceará (FAEC-UECE) durante el semestre 2020.1. En esa ocasión, los estudiantes elaboraron hipótesis para las preguntas sugeridas por el profesor y elaboraron argumentos que corroboraron o no con sus propuestas. Para la recolección de datos se aplicó un cuestionario a través de formularios de Google. Según los datos, los estudiantes evaluaron positivamente el método utilizado para brindar un mejor conocimiento en relación a los contenidos de las asignaturas y para desarrollar una visión crítica de la realidad local. Así, pudimos concluir que la experiencia vivida con el uso de Metodologías Activas en educación remota en las disciplinas de Ecología y Ecología Regional brindó un ambiente adecuado para la producción activa de los estudiantes y el consiguiente aprendizaje.
\end{abstract}

Palabras clave: Aprendizaje remoto de emergencia; Enseñanza de la ecología; Metodologías de enseñanza.

\title{
1. Introdução
}

No final de 2019, o mundo foi surpreendido com o surgimento da pandemia da COVID-19, que atingiu países do mundo inteiro poucos meses depois. Embora a humanidade tenha presenciado outras pandemias em séculos anteriores, a geração atual não tinha a ideia exata dos impactos que esse vírus poderia causar nas vidas das pessoas, sejam eles econômicos, sociais ou psicológicos. Devido à necessidade do distanciamento social para diminuir a transmissibilidade do novo Coronavírus, vários setores foram obrigados a pararem suas atividades presenciais, exceto os setores que desenvolviam atividades consideradas essenciais. Todavia, mesmo os setores considerados não essenciais foram obrigados a encontrar outras formas de realizar suas atividades, como, por exemplo, as instituições de ensino, que não pararam os processos educativos.

Diante desta necessidade, as instituições de ensino deram continuidade aos processos educativos por meio do ensino remoto. Dada a importância desse modo de ensino no contexto de distanciamento social, os órgãos reguladores da educação se manifestaram a favor de sua utilização. Em 29 de maio de 2020, o Ministério da Educação homologou dois pareceres emitidos pelo Conselho Nacional de Educação (CNE), sendo eles favoráveis à computação de atividades pedagógicas não presenciais e a reorganização do calendário escolar (Martins \& Almeida, 2020).

As adaptações ao Ensino Remoto Emergencial (ERE) foram necessárias para todas as instituições de ensino, da educação básica a superior. Desta forma, as universidades e faculdades também tiveram que fazer adaptações nos aspectos regulatórios. Na Universidade Estadual do Ceará - UECE, por exemplo, as atividades educacionais (aulas e demais atividades acadêmicas) por meio remoto passaram a ser obrigatórias nos semestres 2020.1 (Resolução No 4544/2020-CEPE-UECE, de 24 de setembro de 2020) (Universidade Estadual do Ceará-UECE, 2020), 2020.2 (Resolução No 4597/2021 - CEPE-UECE, de 15 de fevereiro de 2021) (UECE, 2021a) e 2021.1 (Resolução No 4635/2021 - CEPE-UECE, de 09 de julho de 2021) (UECE, 2021b).

Além dos aspectos legais, surgiram outras questões e dificuldades que foram consideradas no ensino remoto. Primeiramente foi reconhecer a diferença entre o ERE e a modalidade de Educação à Distância $(\mathrm{EaD})$. Na modalidade $\mathrm{EaD}$ os professores contam com um sistema estruturado, com aparato tecnológico adequado e com metodologias próprias de ensino e aprendizagem (Martins \& Almeida, 2020). Além disso, a EaD é ofertada para um grupo restrito de pessoas que se adequam e precisam desse modo de ensino. O ensino remoto, por outro lado, é a alternativa para a educação em massa no tempo de isolamento social. Diante dessa necessidade, professores e estudantes tiveram que se adequar à realidade online, com a transferência da didática, de metodologias e práticas pedagógicas presenciais para o ensino remoto (Moreira, Henriques \& Barros, 2020), sendo necessário se apropriarem de conhecimentos e recursos tecnológicos. Os professores foram obrigados a 
intensificar o uso das novas tecnologias como ferramentas de ensino, bem como a aprender novas formas de transmitir e construir conhecimento (Guedes et al., 2021).

Embora tenha sido a única opção diante do contexto de isolamento social imposto pela pandemia, a prática de ensino por meio do uso de recursos tecnológicos significou um desafio para os professores e para os estudantes, sobretudo aqueles que fazem parte da população desfavorecida economicamente, o que a torna, segundo Silva, Silva e Santos (2020), mais excludente do que inclusiva. Adicionalmente, Joye, Moreira e Rocha (2020) destacam a necessidade de acesso à internet de qualidade e o aprimoramento dos docentes quanto ao uso dos recursos tecnológicos disponíveis. Nesse contexto, pode ocorrer a segregação da população desfavorecida economicamente (Boto, 2021), pois uma grande parcela de jovens não tem acesso à internet de qualidade (Silva, Silva \& Santos, 2020). A falta de internet e computadores em casa é uma realidade, principalmente dos estudantes da educação pública, mas pode afetar também outra parcela que sempre teve acesso a essas tecnologias devido ao agravamento da crise econômica (Boto, 2021).

Dentre as dificuldades vivenciadas pelos docentes no ensino remoto, destaca-se a falta de domínio no uso das tecnologias, internet instável e de baixa qualidade e, principalmente, sobrecarga de trabalho e desmotivação dos estudantes, o que resulta, muitas vezes, no abandono ou em baixa aprendizagem. Outros acontecimentos menos perceptíveis também podem ser verificados, como a ansiedade, além de perturbações sociais e emocionais devido à mudança na rotina da escola, ao isolamento social e à crise econômica atual (Jacob, 2021).

Diante desse contexto, tem-se discutido e adotado diferentes estratégias para minimizar os impactos na qualidade da educação, na vida de professores e estudantes, além de estimular e envolver os discentes no processo de ensino e aprendizagem. Na UECE, por exemplo, os docentes foram orientados por meio de resoluções aprovadas pelo Conselho de Ensino e Pesquisa (CEPE-UECE) a desenvolverem suas atividades de modo síncrono e assíncrono.

As atividades síncronas ocorrem por meio de ferramentas que permitem, mesmo à distância, a interação e a discussão em tempo real entre professor e aluno, tais como chat e teleconferências (Mendonça \& Gruber, 2019). Por outro lado, as ferramentas assíncronas ocorrem sem a conexão e interação simultâneas entre professor e aluno, onde os discentes desenvolvem suas atividades no seu tempo e ritmo (Piffero, Coelho, Soares \& Roehr, 2020; Spalding et al., 2020). Face a este contexto, Martins e Almeida (2020) sugerem:

Que as tecnologias utilizadas sejam interfaces de construções conjuntas, de formas síncronas e assíncronas, potencializando os debates, o pensamento crítico, a criatividade, o fazer em conjunto, as reflexões a respeito da experiência social imposta pela pandemia, a comunicação efetiva e amorosa, o currículo integrado com a realidade dos estudantes, atos de currículo multidisciplinares que reúnam professores, projetos que possam ser realizados para encontrar soluções para problemas contemporâneos e tantas outras discussões necessárias para uma educação de qualidade e que se tornam essenciais à formação do cidadão pronto para lidar com o novo mundo que está por vir (Martins \& Almeida, 2020. p. 223)

Com base no exposto, optou-se pelo uso de metodologias ativas, que segundo Diesel, Baldez e Martins (2017), possibilitam incentivar o aprendizado dos estudantes, mudando sua posição de expectador para o centro do processo. Esse modelo de ensino era utilizado antes mesmo da pandemia, por exemplo, em cursos superiores na área de saúde (Silva, Silva \& Santos, 2020) e vem sendo pesquisado em instituições de ensino superior durante o ensino remoto (Almeida, 2020; Oliveira, Fernandes \& Andrade, 2020). O envolvimento do aluno no processo de ensino-aprendizagem, colocando-o como protagonista na busca do conhecimento por meio da educação crítica-reflexiva representa o principal elemento das metodologias ativas (Ventura, 2021; Macedo et al., 2018). Ademais, possibilitam a contextualização das vivências e da realidade dos estudantes e, por isso, são consideradas um método inovador que pode ser utilizado no contexto de ensino remoto (Piffero et al., 2020).

O uso de metodologias ativas no contexto de ensino híbrido - parte presencial e parte não presencial - tem mostrado resultados satisfatórios no que se refere à apropriação do conhecimento (Silva et al., 2020), indicando ser uma boa opção para a 
realidade de aulas totalmente remotas. Diante disso, para as disciplinas de Ecologia e Ecologia Regional do Curso de Licenciatura em Ciências Biológicas da FAEC-UECE, optou-se em utilizar algumas metodologias ativas por meio de atividades online (Síncronas) e offline (Assíncrona). Portanto, o objetivo deste trabalho foi observar a viabilidade do uso de metodologias ativas com atividades síncronas e assíncronas no contexto de ensino remoto nessas duas disciplinas do Curso de Licenciatura em Ciências Biológicas, da FAEC-UECE.

\section{Metodologia}

As disciplinas de Ecologia e Ecologia Regional foram ofertadas no semestre 2020.1 do curso de Licenciatura em Ciências Biológicas da FAEC-UECE, no município de Crateús-CE. Os conteúdos das disciplinas foram abordados em momentos de atividades síncronas (online) e assíncronas (offline), na proporção de 50\%, conforme orientações previstas na resolução no 4544/2020-CEPE, de 24 de setembro de 2020 (UECE, 2020).

Utilizou-se o método de Metodologias Ativas nas duas disciplinas. Para isso, no início do semestre, o professor elaborou situações/problemas relacionadas à realidade dos estudantes. Os estudantes foram orientados a proporem hipóteses para as situações/problemas apresentadas e a realizarem levantamento de dados locais e pesquisas bibliográficas para elaborarem argumentos que corroborassem ou não com as hipóteses apresentadas pelo docente. Sugeriu-se alguns eixos norteadores para o levantamento dos dados da realidade local. Os estudantes foram divididos em grupos (Três por disciplina) que se reuniram virtualmente utilizando a ferramenta Google Meet.

Todas as atividades relacionadas ao levantamento de dados locais, pesquisa bibliográfica e elaboração da argumentação foram realizadas no momento das atividades assíncronas, onde os estudantes tinham a condição de escolher o horário mais conveniente para eles. A apresentação dos dados e dos resultados aconteceu em dois encontros online (Síncronos), sendo o primeiro para apresentação das hipóteses e o segundo para a apresentação, discussão e argumentação dos resultados. Os encontros online aconteceram semanalmente por meio do Google Meet e teve como finalidade, além da apresentação dos grupos, a exposição teórica dos conteúdos previstos nos programas das disciplinas e orientação sobre as atividades de pesquisa. Além disso, os estudantes contaram com a possibilidade de pedir orientação ao professor por meio do WhatsApp.

Para a coleta de dados dessa pesquisa, aplicou-se um questionário por meio do Google Forms. Participaram desse levantamento 11 estudantes, sendo cinco da disciplina de Ecologia e seis da Ecologia Regional. Além disso, considerou-se as apresentações dos grupos, identificando os pontos importantes dos argumentos e o relatório produzido e enviado no final do semestre. Para manter o anonimato dos entrevistados, a identificação utilizada na apresentação e discussão dos resultados foi pela letra alfabética "A" seguida por um número, tendo as identificações A1, A2, ... A11.

\section{Resultados e Discussão}

Os/as entrevistados/as concordaram com a distribuição das aulas entre atividades síncronas e assíncronas, sendo que $82 \%$ concordaram totalmente e $18 \%$ parcialmente. Os discentes se manifestaram de forma satisfatória em relação à divisão das atividades síncronas e assíncronas, destacando-se os seguintes pontos: que a atividade síncrona garante o contato (mesmo que virtual) com o professor, sendo necessária no processo de ensino-aprendizagem, enquanto a atividade assíncrona não sobrecarrega o aluno; que ambas facilitam o aprendizado; que ambas incentivam a pesquisa; que para o aluno com dificuldade de acesso à internet e a equipamento é importante, pois as atividades assíncronas podem ser realizadas offline e de acordo com a disponibilidade de tempo do aluno, conforme pode ser constatado nas respostas a seguir. 
A1- As aulas síncronas foram importantes pois o contato direto com o professor possibilita uma dinâmica mais didática e facilita o entendimento. Já nas assíncronas todo o processo da problemática elaborada para nos incentivar a pesquisa foi de grande aprendizado e bastante produtiva;

A2- As duas propostas são eficientes quando falamos do ensino remoto. Porém, a utilização exclusiva da proposta síncrona mais prejudica do que ajuda. Para utilizar dessa proposta é necessário tanto o professor quantos os alunos possuírem equipamentos tecnológicos que atendam à demanda, e uma boa conexão de internet. O que não é nem de longe a realidade que vivemos dentro da universidade;

A2- A utilização conjunta das duas propostas permite ao aluno se organizar para acompanhar a disciplina em termos de conexão e acompanhamento dos momentos presenciais e entrega das atividades nas datas acordadas. Com relação ao aprendizado, as duas propostas se complementam. Utilizar apenas uma é excludente para alguns estudantes;

A3- As duas formas podem trazer conhecimento basta os alunos se esforçarem;

A4- São boas, desde que se adequem ao contexto de cada disciplina. Isso vai depender da realidade das diferentes disciplinas, a exemplo de ecologia regional, foi muito bom e não foi cansativo. Pois uma complementou a outra e possibilitou revisão o conteúdo além do momento da aula.

A5- São necessárias para a realização das atividades durante o semestre, para que nenhum aluno fique prejudicado, as aulas síncronas são utilizadas para que os alunos possam ter acesso ao conteúdo de forma digital e em tempo real, com professores e alunos, e as assíncronas de certa forma, beneficia aqueles alunos que não podem participar das atividades em um tempo online, pois muitas vezes não tem acesso a internet em uma hora específica.

A6- As aulas durante o semestre realizadas de forma síncronas e assíncronas me beneficiou em $90 \%$ para compreensão do conteúdo.

A7- Atividades síncronas são essenciais, pois são as que mais se aproximam das aulas presenciais, estimulam o aprendizado dos alunos. Atividades assíncronas são fundamentais para que se possa exercitar tudo o que foi estudado na teoria.

A8- Em relação às duas propostas pedagógicas avalio como extremamente importante, as quais têm que ser aplicadas juntas de forma a melhorar a aprendizagem dos alunos. Para o meu aprendizado avalio com um 9, pois fiquei muito satisfeita com essas metodologias.

A9- $O$ modo síncrono é onde a gente pode ter o contato com o professor que vai ministrar a aula ao vivo naquele momento e vai tirar todas as nossas dúvidas acerca do conteúdo. Na modalidade assíncrona é onde nós vamos ter um tempo para que possamos desenvolver as atividades que foram propostas para a gente. E nessa disciplina eu achei essa metodologia fundamental para o meu aprendizado, pois não fiquei tão cansado como ficaria se fosse totalmente síncrono.

A10- Ambas as propostas pedagógicas avaliam de alguma forma ou contribui para a obtenção de um ensino mais regular e completo. Se de uma forma a gente tem um tempo de aula com o professor, logo depois teremos um tempo para conseguir realizar as atividades propostas por ele. Dessa forma, não fica tão cansativo.

A falta de acesso à internet de boa qualidade e de tecnologias é uma realidade para a população desfavorecida economicamente (Boto, 2021; Silva, Silva \& Bastos, 2020), o que dificulta o aprendizado da maioria dos estudantes. Desta forma, o momento assíncrono se destaca como uma boa alternativa, pois as atividades podem ser realizadas em momento offline e de acordo com a disponibilidade de tempo dos discentes. Outro aspecto importante em relação à utilização de atividades assíncronas é o sentimento de menor pressão ou de sobrecarga relatado pelos discentes. Essa observação é importante no contexto de isolamento social e de tantas perdas, pois é provável que os discentes estejam em situações de ansiedade e perturbação social e emocional causadas por essa crise (Jacob, 2021). No entanto, é necessário identificar qual a melhor distribuição de horas/aula entre atividades síncronas e assíncronas. Neste aspecto, a maioria dos estudantes (73\%) considera que o ideal seria $50 \%$ de atividades síncronas e $50 \%$ de aulas assíncronas, conforme estabelecido na Resolução $\mathrm{N}^{\circ}$ 4544/2020-CEPE, de 24 de setembro de 2020, da Universidade Estadual do Ceará-UECE (UECE, 2020). Um grupo menor 
(18\%) considerou que o ideal seria a proporção de 60\% de atividades síncronas e 40\% de assíncronas (Figura 1), A maioria $(91 \%)$ considerou que a divisão dos conteúdos em atividades síncronas e assíncronas favoreceu o aprendizado, sendo que a metade desta considerou que foi cansativo e a outra afirmou que não foi cansativo.

Figura 1: Sugestões dos discentes em relação à distribuição do tempo entre atividades síncronas e assíncronas.

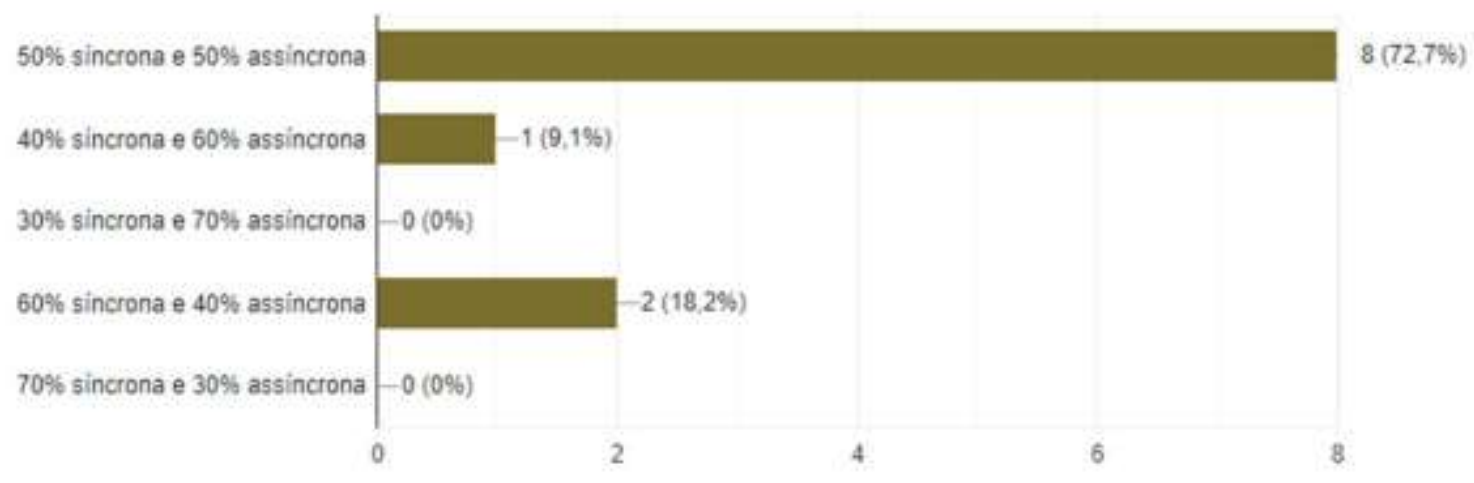

Fonte: Autores (2021).

É importante destacar que esse resultado tem como parâmetro o contexto atual, onde é obrigatório o ensino remoto, como constatado pelo A6: “Apesar de não ser da melhor forma é, talvez, a única forma de ministrar a disciplina nesse momento". Os estudantes consideram que a distribuição dos conteúdos foi adequada, pois de acordo com suas manifestações, não ficou cansativo, facilitou o aprendizado e os momentos de pesquisa e apresentação para turma é importante para o aprendizado.

A1- Todo o conteúdo foi ministrado de maneira adequada de forma a não haver dúvidas;

A2- A distribuição dos conteúdos neste formato permitiu uma maior interação com a pesquisa e o complemento das informações obtidas durante as apresentações foi algo legal;

A3- A distribuição foi boa porque não foi algo cansativo, mas ao mesmo tempo não deu pra absorver tanto conhecimento;

A4- Porque não houve sobrecarga de conteúdo;

A5- Todas as atividades e os conteúdos trabalhados durante o semestre foram repassados de forma clara e em momentos de aulas síncronas e assíncronas.

A6- Os conteúdos sempre foram repassados da melhor forma possível, de forma a facilitar o entendimento;

A7- Diante da situação que vivemos, vejo que o conteúdo foi distribuído de forma adequada e satisfatória;

A8- Com essa distribuição conseguimos terminar todo o conteúdo com antecedência e ficamos focados apenas na produção do artigo;

A9- A distribuição do conteúdo foi feita de forma justa e conseguiu abordar de forma adequada a disciplina para os alunos;

A10- Eu particularmente absorvi o conteúdo, pois foi uma disciplina bem estruturada;

A11- Foi proveitoso. 
A maioria dos discentes $(54,5 \%)$ fez uma ou mais disciplinas com atividades totalmente síncronas. A metade desses relatou que foi cansativo e não favoreceu o aprendizado, e 33,3\% afirmou que foi cansativo, mas favoreceu a aprendizagem (Figura 2). Tal observação se repetiu quando os estudantes avaliaram seu aprendizado, onde 50\% atribuiu nota menor (33,3\%) ou igual $(17,7 \%)$ a 7 , que é a média para aprovação na disciplina. Tal resultado indica que, na opinião dos estudantes, realização simultânea de atividades síncronas e assíncronas se mostra mais adequada para o ensino remoto.

Figura 2: Opiniões dos estudantes em relação às atividades totalmente síncronas.

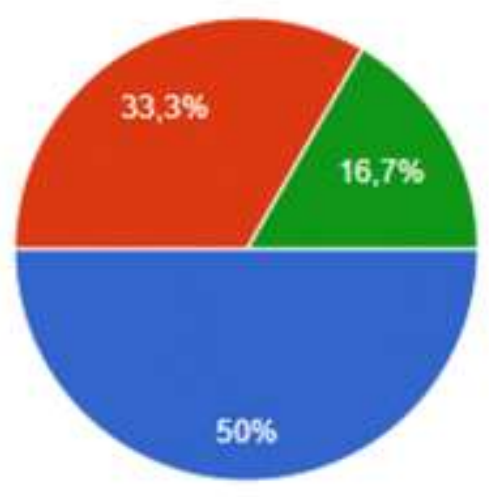

FOI cansativa e NÃO favoreceu o aprendizado

FOI cansativa, MAS favoreceu 0 aprendizado

NÃO foi cansativa e NÃO favoreceu 0 aprendizado

NÄO foi cansativa e favoreceu 0 aprendizado

Fonte: Autores (2021).

É importante observar elementos no contexto da pandemia e pensar as formas de atividades síncronas e assíncronas, no sentido de possibilitarem as construções conjuntas, os debates e a criatividade (Martins \& Almeida, 2020), resultando na visão crítica da realidade de estudantes e professores. Com esse pensamento, optou-se pelo uso de metodologias ativas para a abordagem dos conteúdos das disciplinas de Ecologia e Ecologia Regional. Ao avaliar o uso desse modelo, a maioria dos estudantes considerou adequado o uso de metodologias ativas no contexto do ensino remoto, sendo que $36,4 \%$ consideraram parcialmente e 63,6\% afirmaram ser totalmente adequado.

Para eles, a discussão das questões relacionadas ao contexto dos alunos possibilitou o conhecimento $(45,5 \%)$ e a reflexão crítica da realidade local $(18,2 \%)$, além de facilitar a compreensão de conteúdo $(36,4 \%)$. Em relação à auto avaliação sobre o aprendizado, a maioria respondeu que lhe atribuiria uma nota igual ou acima de 7 (82\%), sendo que $54,6 \%$ desses consideraram uma nota entre 9 e 10. A partir da avaliação dos estudantes, consta-se que metodologias ativas no modelo de atividades síncronas e assíncronas no ensino remoto contribuem com o aprendizado, que vai além do conteúdo das disciplinas. É importante enfatizar que o método de metodologias ativas é utilizado antes mesmo da pandemia e que nesses estudos verificou-se que a utilização desse método no ensino híbrido em cursos superiores tem resultado na ampliação do conhecimento (Silva, Silva \& Santos, 2020).

Além do que já foi apresentado e discutido, os entrevistados consideraram que a utilização de metodologias ativas no modelo de atividades síncronas e assíncronas contribui para formação acadêmica (Formação docente), conhecimento mais amplo sobre ecologia, sobre os aspectos culturais, contextualização e interação com outras áreas das ciências e aperfeiçoamento da escrita acadêmica, já que tiveram que elaborar argumentos para defender ou refutar as hipóteses que eles propuseram.

A partir das observações feitas durante as apresentações e discussão em grupos, é possível concordar com as observações anteriores em relação à aprendizagem. Para fazer essa avaliação considerou-se algumas questões destacadas por 
Anastasiou e Alves (2004) quando sugerem que se os estudantes tiveram o entendimento do conteúdo da disciplina, demonstraram segurança e conexão das ideias durante as apresentações e correlacionaram o conteúdo a realidade local, todos esses fatores juntos, geraram conhecimento e representaram sucesso da estratégia metodológica adotada. Durante as atividades, os estudantes demonstraram capacidade de relacionar o conteúdo das disciplinas à realidade local, inclusive com análise crítica. Como exemplo, podemos citar uma situação posta por um dos grupos em que, ao descreverem os diferentes tipos de agricultura praticados na região (Tradicional, convencional e agroecológica), concluíram que a agricultura agroecológica mantém maior parte características dos ecossistemas naturais e, por isso, é a mais adequada do ponto de vista da sustentabilidade ambiental. Ademais, os estudantes tiveram a oportunidade de exercitar a escrita científica por meio da elaboração dos relatórios no final da disciplina, fato observado a partir da leitura dos mesmos e reconhecido por todos os entrevistados.

Como o curso é de formação de professores, quando os estudantes foram indagados se pretendem utilizar o método de metodologias ativas no exercício da docência, $88 \%$ afirmaram que utilizarão totalmente e $12 \%$ parcialmente (Figura 3). O nível de satisfação dos estudantes e a manifestação do desejo de adotar metodologias ativas na sua prática docente indicam a eficiência desse método, sendo importante discutir essa proposta nos cursos de formação de professores. O uso de metodologias ativas como mecanismo no processo formativo dos seus estudantes já é uma prática em instituições de ensino superior, inclusive com programa de formações continuadas com o objetivo de instrumentalizar os docentes na adoção desse método de ensino (Parada, Portal, Rodrigues \& Borb, 2010). A adoção desse método é crescente, como constatado por Barbosa, Viegas e Batista (2020) ao observar que $85,5 \%$ dos docentes do ensino superior de universidades públicas e privadas da região metropolitana da capital do Rio de Janeiro utilizam metodologias ativas. No entanto, essa não é a realidade na região semiárida, muito provavelmente devido ao desconhecimento pela maioria dos docentes, principalmente os da educação básica.

Figura 3: Manifestações dos discentes sobre a utilização de Metodologias Ativas na sua prática docente.

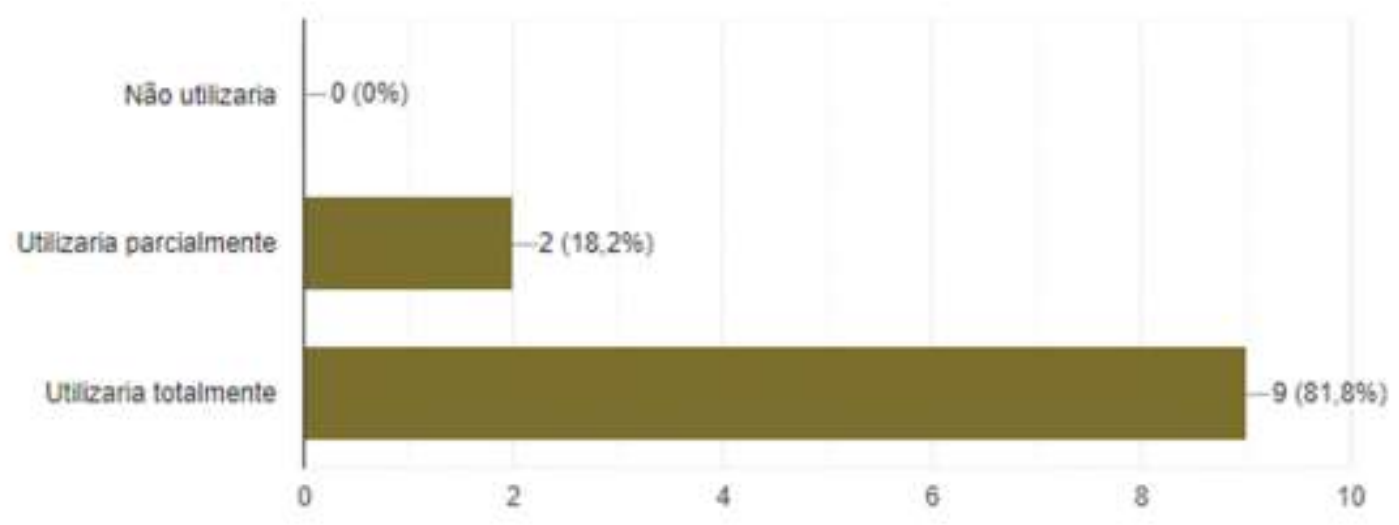

Fonte: Autores (2021).

Nos comentários sobre a utilização de metodologias ativas, conforme algumas descrições destacadas abaixo, fica evidente que os entrevistados consideram importante para o pensamento reflexivo e investigativo sobre o conteúdo, que facilita a compreensão do conteúdo, que estimula a participação, que é importante para conhecer a realidade local, e que os estudantes tornam-se protagonistas do seu aprendizado. . As percepções dos estudantes indicam que o método utilizado é adequado para uma educação não presencial de qualidade, por considerar a aprendizagem ativa dos estudantes, por meio da leitura, da discussão e resolução de problemas, e do pensamento reflexivo, como sugeriram Maciel et al. (2020). 
A1- Utilizaria sim, pois acho uma alternativa bastante importante para a compreensão dos estudantes, a contextualização é de fundamental importância para o processo de ensino-aprendizagem;

A2- Sim, é uma maneira de fazer o aluno começar a ter um pensamento reflexivo e investigativo sobre o assunto;

A3- Por ser um processo que estimula a pensar e refletir;

A5- Facilita a compreensão do conteúdo;

A6- Essas metodologias facilitam e despertam o interesse do aluno em aprender;

A7- Achei incrível esse método de ensino, onde o aluno é protagonista do seu aprendizado. E com certeza irei levar essa metodologia para as minhas futuras aulas;

A8- É uma forma alternativa de ensino que estimula a pesquisa por investigação no estudante, contribuindo para a sua melhor formação;

A9- Sim, pois é muito importante saber sobre determinados situações aos locais no qual vivemos e contribuindo para o ensino por investigação;

A10- É uma maneira de incentivar nos alunos a participarem.

Observa-se o reconhecimento dos princípios básicos da metodologia ativa, como o protagonismo dos estudantes, além do estímulo à reflexão e visão crítica da construção do conhecimento e da realidade do discente. O professor, neste contexto, deve ser o mediador, incentivador e o garantidor de que todo o processo pedagógico resulte no aprendizado e atinja as metas estabelecidas previamente (Nascimento \& Rosa, 2020). Para tanto, é necessário que o professor exponha situações/problemas provocativas a partir da realidade local, de tal modo que permita os estudantes se apropriarem do conteúdo e, ao mesmo tempo, possam analisar criticamente a sua realidade.

\section{Considerações Finais}

No contexto de isolamento social, onde o ensino remoto representa a única opção no processo de transmissão de conteúdo, é necessário observar as condições de todos e todas no processo de ensino e aprendizagem, incluindo professores, estudantes, família e sociedade. É importante observar em qual contexto a instituição de ensino, os estudantes, os professores e a sociedade se encontram. É necessário considerar as condições mínimas necessárias, como o acesso à internet e à tecnologia de qualidade, mas também outros aspectos importantes, como a construção do conhecimento, contextualização dos conteúdos, análise crítica da realidade e as condições psicológicas de estudantes e professores. Neste aspecto, a utilização de Metodologias Ativas no modelo de atividades síncronas e assíncronas mostrou-se promissora para o ensino remoto.

A divisão das aulas no modelo de atividades síncronas e assíncronas se mostrou adequado, sobretudo para os estudantes que não têm acesso à internet com qualidade e estabilidade. Outra observação sobre esse modelo é a maior flexibilidade em relação ao tempo de dedicação à disciplina, pois as atividades assíncronas podem ser realizadas considerando a melhor programação para o estudante. Esses aspectos citados diminuem a pressão sobre os estudantes, refletindo positivamente nas condições emocionais dos mesmos. Por outro lado, os encontros online possibilita a interação entre professor-aluno e aluno-aluno, viabilizando a discussão dos conteúdos por todos e todas, e possibilita, dependendo da metodologia utilizada pelo professor, o fortalecimento da argumentação dos discentes. No caso das disciplinas de Ecologia e Ecologia Regional, parte dos encontros online foi dedicada à apresentação, à discussão e à argumentação dos resultados das atividades assíncronas.

A utilização de Metodologias Ativas foi bem aceita pelos estudantes que consideram este modelo adequado para o ensino remoto, destacando-se a contribuição para o aprendizado e visão crítica da realidade na qual estão inseridos. Para tanto, 
é necessário apresentar questionamentos relacionados à realidade local, com indicação de aspectos que norteiam os estudantes durante a pesquisa. Dessa forma, considerando o que foi exposto neste trabalho, o modelo de Metodologias Ativas com atividades síncronas e assíncronas mostrou-se viável e apropriado para o processo educacional no contexto de ensino remoto.

\section{Referências}

Almeida, M. C. R. (2020). Práticas pedagógicas mediadas por tecnologias digitais em período de pandemia. Revista Docência do Ensino Superior, 10, 1-20. https://doi.org/10.35699/2237-5864.2020.24827

Anastasiou, L. G. C. \& Alves, L. P. Estratégias de ensinagem (2004). In:Anastasiou, Léa das Graças Camargos; Alves, Leonir Pessate (Orgs.). Processos de ensinagem na universidade. Pressupostos para as estratégias de trabalho em aula. (3a ed.), Univille. 67-100. https://edisciplinas.usp.br/pluginfile.php/2547831/mod_resource/content/1/Processos\%20de\%20Ensinagem.pdf

Barbosa, A. M., Viegas, M. A. S. \& Batista, R. L. N. F. F. (2020). Aulas presenciais em tempos de pandemia: relatos de experiências de professores do nível superior sobre as aulas remotas. Rev. Augustus, 25(51), 255-280. https://doi.org/10.15202/1981896.2020v25n51p255

Boto, C. A educação e a escola em tempos de coronavírus. Jornal da USP, ano 2020. https://jornal. usp.br/artigos/a-educacao-e-a-escola-em-tempos-decoronavirus/.

Diesel, A., Baldez, A. L. S. \& Martins, S. N. (2017). Os princípios das metodologias ativas de ensino: uma abordagem teórica. Revista Thema, 14(1), 268-288. https://doi.org/10.15536/thema.14.2017.268-288.404

Guedes, A. C. B., Ladislau, C. S., Oliveira, A. C., Cardoso, T. X., Lobato, S. C. S. \& Silva, F. N. L. (2021). Ensino-aprendizagem em ambiente virtual: a experiência dos docentes no Marajó, Brasil. Research, Society and Development, 10(11), e41101117673. https://doi.org/10.33448/rsd-v10i11.17673

Jacob, E. As consequências da pandemia na educação podem ser piores que o esperado. Recuperado em https://www.jacobsconsultoria.com.br/post/asconsequ \% $3 \%$ AAncias-da-pandemia-na-educa\%C3\%A7\%C3\%A3o-podem-ser-piores-que-o-esperado. Acesso em: 05 jul. 2021.

Joye, C. R., Moreira, M. M. \& Rocha, S. S. D. (2020). Educação a Distância ou Atividade Educacional Remota Emergencial: em busca do elo perdido da educação escolar em tempos de COVID-19. Research, Society and Development, 9(7), 521974299. 10.33448/rsd-v9i7.4299

Macedo, K. D. D. S., Acosta, B. S., Silva, E. B. D., Souza, N. S. D., Beck, C. L. C. \& Silva, K. K. D. D. (2018). Metodologias ativas de aprendizagem: caminhos possíveis parainovação no ensino em saúde. Escola Anna Nery, 22(3), e20170435. https://doi.org/10.1590/2177-9465-EAN-2017-0435

Maciel, M., A., C., Andreto, L. M., Ferreira, T. C. M. Mongiovi, V. G., Figueira, M. C. S., Silva, S. L., Santos, C. S. \& Ferreira, L. L. (2020). Os desafios do uso de metodologias ativas no ensino remoto durante a pandemia do covid-19 em um curso superior de enfermagem: um relato de experiência. Braz. $J$. of Develop., 6(12), p. 98489-98504. https://doi.org/10.34117/bjdv6n12-367

Martins, V. \& Almeida, J. (2020). Educação em tempos de pandemia no Brasil: saberes fazeres escolares em exposição nas redes e a educação on-line como perspectiva. Revista de Educação, 4(2), 215-224. https://doi.org/10.12957/redoc.2020.51026

Mendonça, I. T. M., \& Gruber, C. (2019). Interação síncrona na Educação a Distância a partir do olhar dos estudantes. Informática na educação: teoria \& prática, 22(2), p. 159-174. https://doi.org/10.22456/1982-1654.88643

Moreira, J. A. M., Henriques, S. \& Barros, D. (2020). Transitando de um ensino remoto emergencial para uma educação digital em rede, em tempos de pandemia. Dialogia, 34, 351-364. 10.5585/Dialogia.N34.17123

Nascimento, F. G. \& M. Rosa, J. V. A. Princípio da sala de aula invertida: uma ferramenta para o ensino de química em tempos de pandemia. Braz. J. of Develop., 6(6), p.38513-38525. https://doi.org/10.34117/bjdv6n6-409

Oliveria, J. F. A. C., Fernandes, J. C. C. \& Andrade, E. L. M. (2020). Educação no contexto da pandemia da Covid-19: adversidades e possibilidades. Itinerarius Reflectionis, 16 (1), 1-17. https://doi.org/10.5216/rir.v16i1.65332

Parada, A. R., Portal, V. M. S., Rodrigues, M. A. T. \& Borb, E. Z. (2020). O uso de metodologias ativas no ensino remoto com alunos de uma IES durante a pandemia do Covid-19. FACCAT, 9(1), 137-151. https://seer.faccat.br/index.php/redin/article/view/1875

Piffero, E. de L. F., Coelho, C. P., Soares, R. G. \& Roehr, S. R. (2020). Metodologias ativas e o ensino remoto de biologia: uso de recursos online para aulas síncronas e assíncronas. Research, Society and Development. 9 (10), e719108465. 10.33448/rsd-v9i10.8465

Silva, E. H. S., Silva, J. G. N. \& Santos, M. C. S. (2020). Pedagogia da pandemia: reflexões sobre a educação em tempos de isolamento social. Revista LatinoAmericana de Estudos Científicos, 1(4), 29-44. https://periodicos.ufes.br/ipa/article/view/31695

Spalding, M., Rauen, C., de Vasconcellos, L. M. R. C., Vegian, M. R., Miranda, K. C., Bressane, A. \& Salgado, M. A. C. (2020). Desafios e possibilidades para o ensino superior: uma experiência brasileira em tempos de COVID-19. Research, Society and Development, 9(8), e534985970-e534985970.

Universidade Estadual do Ceará-UECE. Resolução № 4544/2020-CEPE-UECE, de 24 de setembro de 2020. (UECE, 2020). Regulamenta, em caráter excepcional, a oferta especial de disciplinas e de outros componentes curriculares da graduação, por meio remoto, no semestre2020.1. http://www.uece.br/wpcontent/uploads/2020/09/RES.-4544-CEPE.pdf

Universidade Estadual do Ceará-UECE. Resolução No 4597/2021 - CEPE-UECE, de 15 de fevereiro de 2021. (UECE, 2021a). Regulamenta, em caráter excepcional, a oferta especial de disciplinas e de outros componentes curriculares da graduação, por meio remoto, no semestre 2020.2. http://www.uece.br/wpcontent/uploads/2021/03/RES-4597-CEPE.pdf 
Research, Society and Development, v. 10, n. 12, e341101220440, 2021

(CC BY 4.0) | ISSN 2525-3409 | DOI: http://dx.doi.org/10.33448/rsd-v10i12.20440

Universidade Estadual do Ceará-UECE. Resolução No 4635/2021 - CEPE-UECE, de 09 de julho de 2021). (UECE, 2021b). Regulamenta, em caráter excepcional, a oferta especial de disciplinas e de outros componentes curriculares da graduação, por meio remoto, no semestre 2021.1. http://www.uece.br/wpcontent/uploads/2021/07/RES-4635-CEPE.pdf

Ventura, P. P. B. (2021). Indicadores de metodologias ativas no ensino remoto emergencial. RIET. 2(2), 167-183. https://doi.org10.30612riet.v2i2.14521 